\title{
Evaluating a policy of reduced consultant antenatal clinic visits for low risk multiparous
} women

\author{
A M Hill, P L Yudkin, D J Bull, D H Barlow, F M Charnock, M D Gillmer
}

\begin{abstract}
Objectives-To evaluate a change in antenatal care policy to reduce antenatal clinic visits, whereby low risk multiparous women were managed by the primary care team and seen at booking and at 41 weeks' gestation at the consultant antenatal clinic.
\end{abstract}

Design-Comparative study of low risk multiparous women retrospectively identified through the Oxford obstetric data system and cared for by three consultants who changed their policy (group A) or three consultants who maintained their routine care (group B). Setting-Oxfordshire Health District.

Subjects-2153 low risk multiparous women (1079 group A, 1074 group B) booked for consultant care at John Radcliffe Maternity Hospital between August 1985 and July 1987.

Main measures-Comparison of pregnancy outcomes, satisfaction with care, and clinic waiting times, during one year before and after the policy change (year 1 , year 2).

Results-The proportion of women in group A with only one or two consultant clinic visits increased from $19.9 \%$ to $57.9 \%$ between years 1 and 2 ( $p<0.001)$. Clinic waiting times did not improve. Of five perinatal deaths in group $A$, one (from postmaturity) could possibly be attributed to the policy change. The proportion of women reaching 42 weeks' gestation rose from $4 \cdot 7 \%$ to $9 \cdot 2 \%$ (p< 0.01 ); the proportion fully satisfied with their care rose from $68 \cdot 4 \%$ to $82 \cdot 1 \%$ $(p<0.025)$. No such changes were seen in group B.

Conclusions-The change in policy was successful in reducing hospital antenatal clinic visits. The exercise identified dilemmas around evaluating changes in antenatal care settings.

Implications-Criteria to test policy objectives should be selected carefully and rare events assessed prospectively in order to detect problems early.

(Quality in Health Care 1993;2:152-156)

\section{Introduction}

Overcrowded and impersonal hospital antenatal clinics have been a feature of antenatal care in Britain for many years. ${ }^{1}$
Innovative ways of tackling this problem that have been introduced ${ }^{2-4}$ include a reduction in visits to hospital antenatal clinics.

In John Radcliffe Hospital, Oxford, a proposed solution was to reduce the number of visits to hospital by low risk multiparous women booked for delivery in the consultant unit. The proposal was for a booking visit at 16 weeks' gestation, with no further visits until 41 weeks, unless complications developed. All other routine visits were to be made to the general practitioner and the community midwife. After consultation with general practitioners the policy was adopted by three of the six consultant obstetricians, while the other three maintained their previous style of care.

The hospital's maternity liaison committee asked the Oxfordshire Public Health Medicine Department to evaluate this change in policy. The evaluation was based on the following objectives: without jeopardising the safety of the mother and fetus, to reduce hospital antenatal clinic visits and waiting times in hospital clinic and to increase satisfaction with antenatal care. Although this change in policy is not controversial, we report this study in order to describe the experience of undertaking such an evaluation.

\section{Methods}

This study was approved by the Central Oxford Research Ethics Committee in August 1986. General practitioners referring women to the consultants who were changing their policy were consulted about the change in policy by letter. No objections were received.

POLICY ON ANTENATAL CARE

Before 1 August 1985 standard antenatal care for low risk multiparous women booking for shared care entailed a booking visit between 10 and 16 weeks' gestation and two or three further visits in the third trimester, with all other care being given by the primary care team. The changed protocol was for consultants to see all women at their booking visit and then not again until 41 weeks' gestation. All other care was to be given by the general practitioner and the community midwife, who were advised to refer the women to the consultant if any complications developed. The change in policy was formally introduced on 1 August 1986; however, one consultant introduced changes in his 
peripheral clinics in April 1986. For comparison, the last 12 months of old style care were deemed to be 1 April 1985 to 31 March 1986 (year 1), and the first 12 months of new style care to be 1 August 1986 to 31 July 1987 (year 2).

We compared women booking during these two 12 month periods, both the women whose consultant changed their antenatal care policy (group A) and, to detect trends in care that were independent of the change in policy, women whose consultant maintained routine care throughout (group B). Table 1 shows the study design.

\section{SOURCES OF DATA}

Management of pregnancy and outcomeDetailed and complete information about all deliveries in this hospital is recorded on the computerised Oxford Obstetric Data System. Coding is from the case notes by trained staff, with medical supervision. All low risk multiparous women who booked for shared care during the study periods, who delivered at the hospital, were identified retrospectively by the obstetric data system, with criteria specified by the participating consultants (box). Details of the outcome of pregnancy for the women selected for the study were obtained from the obstetric data system or (when they were not recorded on the system) from case notes.

Waiting times in clinic-Information on time spent at the hospital antenatal clinics was collected with self completed questionnaires given to all women (not only low risk multiparous women) during three weeks in July 1986 and in July 1987. Women were handed a questionnaire at the start of their clinic visit, which they completed during their visit and returned at the end. This questionnaire ascertained the start and end times of various components of their visit.

Women's opinions of their care were sought through a two page self administered questionnaire handed out before discharge from the postnatal wards, between May and August in both 1986 and 1987. This questionnaire asked how satisfied women were with several aspects of antenatal care they received from the primary care team and the hospital and about the number of visits to the primary care team antenatal clinics, as this information was not available through the obstetric data system. The questionnaires were handed out to all postnatal multiparous women, and those completed by women

Table 1 Study design

\begin{tabular}{|c|c|c|}
\hline Study period & $\begin{array}{l}\text { Women whose consultants } \\
\text { changed policy } \\
(\text { group } A)\end{array}$ & $\begin{array}{l}\text { Women whose consultants } \\
\text { maintained routine care } \\
\text { (group B) }\end{array}$ \\
\hline $\begin{array}{l}\text { Year } 1 \\
\text { (1 April 1985- } \\
31 \text { March 1986) }\end{array}$ & $\begin{array}{l}\text { Booking visit by } 16 \text { weeks' } \\
\text { gestation } \\
2 \text { or } 3 \text { Further visits } \\
\mathrm{n}=526\end{array}$ & $\begin{array}{l}\text { Booking visit by } 16 \text { weeks' } \\
\text { gestation } \\
2 \text { or } 3 \text { Further visits } \\
n=529\end{array}$ \\
\hline $\begin{array}{l}\text { Year } 2 \\
\text { (1 August 1986- } \\
31 \text { July 1987) }\end{array}$ & $\begin{array}{l}\text { Booking visit by } 16 \text { weeks' } \\
\text { gestation } \\
\text { Visit at } 41 \text { weeks' } \\
\text { gestation } \\
\mathrm{n}=553\end{array}$ & $\begin{array}{l}\text { Booking visit by } 16 \text { weeks' } \\
\text { gestation } \\
2 \text { or } 3 \text { Further visits } \\
n=545\end{array}$ \\
\hline
\end{tabular}

categorised as low risk were identified retrospectively, by matching with the women selected from the obstetric data system.

HYPOTHESES TO BE TESTED AND STATISTICAL METHODS

The main change expected to result from the new policy was a reduction in the number of antenatal visits to the hospital. The primary purpose of our study was to examine this change. The numbers in each of the groups for comparison (about 500) were sufficient to detect an increase from $20 \%$ to $30 \%$ in the proportion of women making only one or two clinic visits, at a significance level of 0.02 with $90 \%$ power. It was expected that changes might occur in the number of antenatal inpatient admissions, the rates of pregnancy after term, or the rate of induction of labour. Comparison of these and other outcome measures under the old and the new policies was a secondary aim of the study. Changes in the occurrence of those complications which antenatal care is designed specifically to avoid (such as undetected breech presentation, undiagnosed intrauterine growth retardation, and severe late pre-eclampsia) were also considered possible. However, as the rates of these complications are extremely low among low risk multiparous women this study did not have sufficient power to detect changes in these rates.

To test for significance rates were compared by the $\chi^{2}$ test (or, for small numbers, Fisher's exact test), and means were compared by using the $t$ test. Two tailed tests were used. This study was not designed to test a single hypothesis but rather to explore whether the groups differed in the aspects detailed above. Following convention, we reported results as

\section{Criteria for selecting low risk multiparous women}

(1) Parity 1 to 4

Age 18 to 34 years at booking visit Maternal height $\geqslant 1.52 \mathrm{~m}$

Booked before 20 weeks' gestation

(2) No medical history of:

Chronic bowel disease

Diabetes

Heart disease

Neoplasms

Renal disease

Venous thrombosis

(3) Not receiving long term treatment

(4) No obstetric history of:

Perinatal death

Birth weight $<2500 \mathrm{~g}$

Delivery before 37 weeks' gestation

Severe pre-eclampsia

Placental abruption or severe antepartum haemorrhage

Rhesus or other isoimmunisation

Shirodkar suture

Caesarean section

(5) At booking visit, the following not detected:

Multiple pregnancy

Diastolic blood pressure $\geqslant 90 \mathrm{~mm} \mathrm{Hg}$

Systolic blood pressure $\geqslant 150 \mathrm{~mm} \mathrm{Hg}$

Abnormal $\alpha$ fetoprotein 
Table 2 Number of attendances at hospital antenatal clinics by women in group $A$, excluding women attending peripheral clinics ${ }^{\star}$

\begin{tabular}{lccc}
\hline \multirow{2}{*}{$\begin{array}{l}\text { No of clinic } \\
\text { attendances }\end{array}$} & Year 1 & & Year 2 \\
\cline { 2 - 2 } & No (\%) of women & & No (\%) of women \\
\hline 1 & $11(2 \cdot 6)$ & & $130(30 \cdot 0)$ \\
2 & $73(17 \cdot 3)$ & & $121(27 \cdot 9)$ \\
3 & $144(34 \cdot 2)$ & & $74(17 \cdot 1)$ \\
4 & $102(24 \cdot 2)$ & & $58(13 \cdot 4)$ \\
$\geqslant 5$ & $91(21 \cdot 6)$ & & $50(11 \cdot 5)$ \\
\hline Total & 421 & 433 \\
\hline
\end{tabular}

Source: obstetric data system.

${ }^{\star}$ Clinic visits year $1 v$ year $2 ; \mathrm{p}<0.001$

significant whenever $\mathrm{p}$ was $<0 \cdot 05$. However, because about 50 different significance tests were carried out, there is a very high probability that at least one spuriously "significant" result will have occurred, and the results should be judged in this context.

\section{Results}

Table 1 shows the numbers of women in groups $A$ and $B$ in each year; the characteristics of women in the four groups was not significantly different. For women in group B, who received routine care throughout (table 1), no trend was observed between the two years in most of the outcome measures assessed. The results are therefore not reported except when an important change did occur, when details are given in the relevant section.

\section{HOSPITAL ANTENATAL CLINIC VISITS}

Women attending peripheral antenatal clinics at the time of this study retained their own case notes, and their record in the obstetric data system did not differentiate between attendances at the hospital clinic and peripheral clinics. Women under the care of general practitioners in the catchment area of these peripheral clinics were therefore excluded from the analysis of the number of antenatal clinic visits, though they were included in all other analyses.

In group A women between year 1 and year 2 there was a striking downward shift in the number of antenatal clinic visits overall $(\mathrm{p}<0.001)$ (table 2). The proportion of women in this group making only one or two visits was $19.9 \%$ in year 1 compared with $57.9 \%$ in year 2 (difference $38.0,95 \%$ confidence interval 32.0 to 44.0$) ; 30.0 \%$ of women made only one hospital clinic visit in year 2 whereas previously less than 3\% made only one visit.

Table 3 Size of clinic, response rates to the questionnaire survey, and time spent in clinics for women in group A, fuly 1986 and $\mathfrak{F}$ uly 1987

\begin{tabular}{|c|c|c|c|}
\hline & fuly 1986 & fuly 1987 & $\begin{array}{l}\text { Significance } \\
\text { of difference }\end{array}$ \\
\hline \multicolumn{4}{|c|}{ Booking visits } \\
\hline $\begin{array}{l}\text { No attending } \\
\text { No }(\%) \text { responding to survey } \\
\text { Mean time in clinic (min) } \\
\text { ( } 95 \% \text { confidence interval) }\end{array}$ & $\begin{array}{l}144 \\
126(88) \\
136 \cdot 7(131.0 \text { to } 142 \cdot 4)\end{array}$ & $\begin{array}{l}164 \\
140(85) \\
155 \cdot 7(150 \cdot 2 \text { to } 161 \cdot 2)\end{array}$ & $\mathrm{p}<0.001$ \\
\hline \multicolumn{4}{|c|}{ Follow up visits } \\
\hline $\begin{array}{l}\text { No attending } \\
\text { No }(\%) \text { responding to survey } \\
\text { Mean time in clinic (min) } \\
\text { ( } 95 \% \text { confidence interval) }\end{array}$ & $\begin{array}{l}354 \\
309(87) \\
69 \cdot 0(65 \cdot 4 \text { to } 72 \cdot 6)\end{array}$ & $\begin{array}{l}357 \\
268(75) \\
78.5(73.6 \text { to } 83.4)\end{array}$ & $\mathrm{p}<0.001$ \\
\hline
\end{tabular}

Table 4 No of undiagnosed complications of pregnancy in groups $A$ and $B^{\star}$

\begin{tabular}{lcccccc}
\hline & \multicolumn{2}{c}{ Group $A$} & & \multicolumn{2}{c}{ Group B } \\
\cline { 2 - 3 } \cline { 5 - 6 } & Year 1 & Year 2 & & Year 1 & Year 2 \\
\hline Breech at delivery & 0 & 2 & & 2 & 2 \\
Multiple pregnancy at booking & 0 & 0 & & 0 & 1 \\
Intrauterine growth retardation & 0 & 3 & & 3 & 2 \\
Gestational hypertension & 0 & 0 & & 0 & 0 \\
\hline
\end{tabular}

^Source: obstetric data system.

In the postnatal questionnaire survey the overall response was $89.6 \%$ in year 1 , and $93.4 \%$ in year 2 . In group A 153 women responded in year 1 and 135 in year 2 . From this survey the total number of antenatal visits both to hospital and to the primary care team made by women in this group could be estimated. Though visits to the primary care team increased, the total number of visits did not, the mean number of visits remaining unchanged in years 1 and $2(13 \cdot 0,12 \cdot 4$ to $13 \cdot 6$ and $13 \cdot 0,12 \cdot 3$ to $13 \cdot 7)$.

WAITING TIMES IN HOSPITAL CLINIC

Table 3 shows the numbers of women attending clinics and the response rates to the clinic survey in July 1986 and 1987. The number of new attendances at clinic increased by 20 between the two years (from 144 to 164) whereas the number of follow up visits remained static (354 in year 1, 357 in year 2). The total time spent in the clinic was determined for booking and follow up visits separately, and for both visits the mean time increased significantly (table 3 ). In group B during the same period the length of clinic visit did not increase for booking or for follow up visits.

SAFETY OF MOTHER AND FETUS

Diagnosis of complications of pregnancyTable 4 summarises the detection of complications of pregnancy. All the undiagnosed breech births underwent assisted delivery, and the infants had a satisfactory outcome. One multiple pregnancy was missed at booking in group B but was detected at 28 weeks' gestation by the primary care team. There were no cases of undiagnosed gestational hypertension.

Management of labour-Table 5 shows that between year 1 and year 2 in group A there was a significant shift in the distribution of gestational age $(p<0.01)$ with an increase in both preterm and post-term deliveries. The proportion of women reaching 42 weeks'

Table 5 Gestational age at delivery among women in group $A^{\star}$

\begin{tabular}{lccc}
\hline $\begin{array}{l}\text { Gestational age } \\
\text { (weeks) }\end{array}$ & Year 1 & & Year 2 \\
\cline { 2 - 2 } & No (\%) of women & & No (\%) of women \\
\hline$<37$ & $8(1 \cdot 5)$ & & $19(3 \cdot 4)$ \\
$37-40$ & $362(68 \cdot 8)$ & & $339(61 \cdot 3)$ \\
41 & $131(24 \cdot 9)$ & & $144(26 \cdot 0)$ \\
42 & $22(4 \cdot 2)$ & & $50(9 \cdot 0)$ \\
43 & $3(0 \cdot 6)$ & & $1(0 \cdot 2)$ \\
\hline Total & 526 & 553 \\
\hline
\end{tabular}

Source: obstetric data system.

${ }^{\star}$ Gestational age year 1 v year 2 ; p $<0.01$. 
Table 6 Causes of perinatal and postneonatal deaths in groups $A$ and $B$ before and after change in policy ${ }^{\star}$

\begin{tabular}{|c|c|c|c|c|c|c|}
\hline Group & Year & $\begin{array}{l}\text { Gestation } \\
\text { (weeks) }\end{array}$ & Death & Age at death & Cause of death & Comment \\
\hline $\begin{array}{l}A \\
A\end{array}$ & $\begin{array}{l}2 \\
2\end{array}$ & $\begin{array}{l}28 \\
38\end{array}$ & $\begin{array}{l}\text { Stillbirth } \\
\text { Stillbirth }\end{array}$ & - & Not explained & \multirow{3}{*}{$\begin{array}{l}\text { Intrauterine contraceptive } \\
\text { device in place }\end{array}$} \\
\hline A & 2 & 24 & Neonatal death & 3 Days & Prematurity & \\
\hline A & 2 & 25 & Neonatal death & 1 Day & Abruption, prematurity & \\
\hline A & 2 & 42 & Neonatal death & 5 Days & Intrapartum asphyxia & \multirow{3}{*}{$\begin{array}{l}\text { Seen at clinic at } 41 \text { and } \\
42 \text { weeks' gestation. } \\
\text { Spontaneous rupture of } \\
\text { membranes } \\
\text { Intrauterine retardation }\end{array}$} \\
\hline B & 1 & 37 & Post-neonatal death & 4 Months & Down syndrome & \\
\hline B & 2 & 39 & Stillbirth & $=0$ & Retroplacental haemorrhage & \\
\hline
\end{tabular}

^Source: obstetric data system and case note review.

gestation or more before delivery rose from $4.8 \%$ to $9.2 \%$ (difference $4.4,1.4$ to $7 \cdot 4$ ); the number of women reaching 43 weeks' gestation did not, however show any increase. The methods of delivery were unchanged between the two years in group A.

Neonatal outcome-Table 6 gives the number and causes of deaths in both groups over the two years. In group A 12 babies were admitted to the special care nursery in year 1 and 20 in year 2 , an increase that was not significant.

Women's satisfaction with antenatal care-In the postnatal questionnaire survey women were asked about their satisfaction with care ("Overall, how do you feel about the antenatal care you received in this pregnancy?") and rated their care on a 5 point scale: fully satisfied to dissatisfied. In group $A$ the proportion of women fully satisfied with their care increased from $68.4 \%(104 / 152)$ to $82 \cdot 1 \%(110 / 134)$ (difference $13 \cdot 7,3 \cdot 8$ to $23 \cdot 5$; $\mathrm{p}<0.025)$. The remainder were either fairly satisfied $(21 \cdot 1 \%, 32 / 152 v 9 \cdot 7 \%, 13 / 134)$ or had mixed feelings or were dissatisfied $(10.5 \%, 16 / 152 v 8.2 \%, 11 / 134)$. In group B there was no significant change, with $76.8 \%$ $(106 / 138)$ women were fully satisfied with care in year 1 and $73.2 \%(93 / 127)$ in year 2 (difference $3 \cdot 6,-6 \cdot 9$ to $14 \cdot 0$ ).

\section{Discussion}

This evaluation has been reported, not because the change in policy was radical (which it was not) but because it was evaluated quite rigorously. This discussion focuses on the process of evaluation and on the problems of its interpretation, given that the evaluation looked at two major, and what could be regarded as opposing, dimensions of quality - namely, effectiveness and acceptability.

\section{DATA COLLECTION AND VALIDATION}

As the criteria selected for identifying low risk women were not comprehensive, some women identified may not have been considered for changed care, and vice versa. However, we considered the lack of precision in this selection unlikely to have seriously biased our comparisons.

The method of selection used in this study was unwieldy and imprecise. It would have been of considerable value to identify prospectively, by flagging their records, the women considered by the consultants to be at low risk at booking. This was not possible with the obstetric data system, but it should be a requirement of all computerised clinical audit systems. A consequence of not flagging records was that we were unable to ascertain the extent to which, with the preset criteria, women actually managed as low risk women were correctly identified from the system and women not managed as low risk women were correctly excluded.

We also made no attempt to validate the consistency with which the consultants who changed policy held to the criteria they set. From the limited case note review undertaken for the study, selection of low risk women for the changed style of care was in line with the criteria set, except for systolic blood pressure at the booking visit, when it was apparent that the criterion for exclusion was taken to be $\geqslant 140 \mathrm{~mm} \mathrm{Hg}$, rather than the $150 \mathrm{~mm} \mathrm{Hg}$ set.

The data collection for this evaluation was not straightforward or streamlined. The advent of computerised audit systems should make the evaluation or audit of antenatal care simpler as long as it is possible to flag subsets of women prospectively and as long as the objectives and standards of antenatal care have been agreed and criteria determined and incorporated.

INTERPRETATION OF RESULTS

The aim of the change in policy was to reduce the attendance of low risk multiparous women at consultant antenatal clinics and thus to reduce overall attendance and waiting times at those clinics. Although a substantial reduction in visits made by these women was achieved, there was apparently no accompanying improvement in clinic waiting times. In retrospect, we acknowledge that this expectation was unrealistic because of the modest nature of the policy change. In fact, we observed a lengthening, rather than a reduction, in clinic waiting times, but our results are probably misleading. Although the total number of women surveyed was large, the number of clinics samples was small (nine in each comparison group) and by chance there were fewer medical staff in attendance in the clinics studied in year 2 .

If such a study were repeated we would recommend that, as nearly every woman sees a receptionist to make a further appointment at the end of her clinic visit, the receptionist records the time that the appointment is made (as a proxy for time of departure from the clinic). As waiting times in antenatal clinics 
remain a major cause of concern nationwide, such data should perhaps be collected routinely.

Although the change in policy did not seem to reduce waiting times, it did result in many fewer visits for the low risk women. This is reflected in the increased percentage of women satsified with care received, which is a positive result of this study.

The change in policy had one other major, but unexpected, effect, which was to more than double the percentage of women who reached 42 weeks' gestation (though the small percentage reaching 43 weeks did not change). This change occurred because admission for induction was planned at the vist at 41 weeks and during the study the waiting time for induction was often more than a week. In the previous year arrangements for some women had been made at the visit at 40 weeks' gestation.

The other dimension of the study was the assessment of safety of mother and fetus, and as expected this produced no significant results. One perinatal death occurred in the group of women reaching 42 weeks' gestation, which was attributed to postmaturity. In terms of the policy change the management of this woman had been correct, as she was seen at consultant antenatal clinic at 41 weeks' gestation. However the delay in induction had not been anticipated at the time the policy was determined, and it is possible that under the old policy this death might have been avoided. In addition four further perinatal deaths occurred in group A in year 2, representing a perinatal mortality rate of more than $10 / 1000$ births. None of these deaths were deemed avoidable.

This evaluation resulted in a review of the policy for booking inductions. Otherwise the clinical staff considered that the evaluation supported the continuation of the policy.

\section{METHODOLOGICAL ISSUES}

The design of this evaluation was a comparison between cohorts of women experiencing the same antenatal care but in a different setting (primary care) with different staff (the primary care team). Because the main aim of the study was to reduce hospital clinic attendance and waiting time, with assurance of safety being a secondary aim, we considered this comparative method of evaluation was the most appropriate.

The perinatal deaths and the rates of undiagnosed complications of pregnancy show well the problem of interpretation of rare events. It would be impossible within one hospital to obtain a case series large enough to be able to show significant results for these events. In evaluating a change in antenatal policy these adverse events need to be assessed in other ways, such as by critical event monitoring or case review, in order to detect problems early (such as the problem we experienced with booking induction).

\section{Conclusions and recommendations}

Several quality measures in antenatal care might be considered, from patient satisfaction through to maternal and neonatal outcomes. Different weights may be given to different criteria, depending on the point of view of mother, manager, or professional. This study shows the variety of different criteria that can be used and the problem of their interpretation (rare events in particular). In evaluating antenatal care we would recommend the following:

- That, when a change in antenatal policy entails a change in setting or staff, comparing cohorts (as in this study) is a suitable method for assessment

- That the key criteria used should be undetected complications, perinatal mortality and morbidity, women's satisfaction with care, and time spent in clinic

- That the identification and assessment of rare events should be undertaken continuously rather than analysed retrospectively, in order to detect early any problem arising

- That design of clinical computer systems should include data for evaluation against key objectives and the ability to flag selected records.

We thank those who helped us in this study, in paticular the other consultant obstetricians who were prepared to act as a comparison group, Iain Chalmers and Nick Black for their help comparison group, Iain Chalmers and Nick Black for their help and advice on the design and implementation of the study, and Alice Fuller and Caroline Bass who administered the
questionnaire surveys. This paper would not have been possible without the diligent work of the obstetric data system coders, supervised by Mrs Norma Hegarty. The study was funded by the Oxford Region Locally Organised Research Scheme.

Garcia J. Women's views of antenatal care. In: Enkin M, Chalmers I, eds. Effectiveness and satisfaction in antenatal Chalmers I, eds. Effectiveness and satisfaction in antenatal care. London: Spastics Internation

2 Hall M, Macintyre S, Porter M. Antenatal care assessed: a case study of an innovation in Aberdeen. Aberdeen: Aberdeen University Press, 1985

Flint C, Poulengeris P. "Know your midwife" report. London: South West Thames Regional Health Authority and Wellington Foundation, 1986.

4 Street P, Gannon MJ, Holt EM. Community obstetric care in West Berkshire. BMF 1991;302:698-700.

5 Yudkin PL, Redman CWG. Obstetric audit using routinely collected computerised data. BMF 1990;301:1371-3. 